\title{
Deregulated expression of KRAP, a novel gene encoding actin-interacting protein, in human colon cancer cells
}

Received: 22 September 2003 / Accepted: 30 October 2003/Published online: 13 December 2003

(C) The Japan Society of Human Genetics and Springer-Verlag 2003

\begin{abstract}
We have identified a novel gene, designated $K R A P \quad$ (Ki-ras-induced actin-interacting protein), encoding a protein of 1,259 amino acids with coiled-coil regions and transmembrane regions, from the cDNA library of human colon cancer HCT116 cells, as one of the genes upregulated by activated Ki-ras. While KRAP was rarely expressed in normal colon epithelium, deregulated constitutive KRAP expression was observed in some other colon cancer cells. In normal tissues, KRAP was strongly expressed in pancreas and testis. Anti-KRAP polyclonal antibodies detected endogenous KRAP as the molecular size of $\mathrm{M}_{\mathrm{r}} 180,000$, and immunofluorescence microscopy and cytochalasin E treatment revealed that KRAP was clearly associated with the actin filaments. Furthermore, KRAP was localized as a membrane-bound form with extracellular regions. These results together suggested KRAP might be involved in the regulation of filamentous actin and signals from the outside of the cells.
\end{abstract}

Keywords KRAP $\cdot \mathrm{CS}-1 \cdot \mathrm{Ki}$-ras $\cdot$ Actin filaments · Cancer

\footnotetext{
J. Inokuchi $\cdot$ M. Komiya $\cdot$ I. Baba $\cdot$ S. Shirasawa $(\square)$

Department of Pathology, Research Institute,

International Medical Center of Japan,

1-21-1 Toyama, Shinjuku-ku,

Tokyo 162-8655, Japan

E-mail: sshirasawa@ri.imcj.go.jp

Tel: + 81-3-32027181

Fax: + 81-3-32027364

J. Inokuchi $\cdot$ S. Naito

Department of Urology,

Graduate School of Medical Sciences,

Kyushu University,

3-1-1 Maidashi, Higashi-ku,

Fukuoka 812-8582, Japan

T. Sasazuki

Research Institute,

International Medical Center of Japan,

1-21-1 Toyama, Shinjuku-ku,

Tokyo 162-8655, Japan
}

\section{Introduction}

Ras has been implicated in controlling cell proliferation, differentiation, and apoptosis (Barbacid 1987; Bos 1989; Almoguera et al. 1998; Bos et al. 1987; Forrester et al. 1987). We previously established HCT116-derived cells in which activated Ki-ras was disrupted through gene targeting (Shirasawa et al. 1993) and had reported the several critical molecular mechanisms of the activated Ki-rasmediated signals in tumorigenesis utilizing these cells (Shirasawa et al. 1993; Allgayer et al. 1999; Okada et al. 1998; Rak et al. 1995; Baba et al. 2000; Tsunoda et al. 2002; Okumura et al. 1999). The cleavage signal-1 protein, CS-1, a protein of 249 amino acids reported to be detected as the molecular size of $\mathrm{M}_{\mathrm{r}}$ 33,000 in Western blot using anti-CS-1 polyclonal antibodies, was originally identified as a sperm surface antigen involved in regulation of early cleavage of fertilized eggs (Javed and Naz 1992; Naz 1992). Here we have identified a novel gene, designated KRAP (Ki-ras-induced actin-interacting protein), including $\mathrm{CS}-1$ sequences in the $\mathrm{COOH}$ terminal region. $K R A P$ was overexpressed through the activated $\mathrm{Ki}$-rasmediated signals in HCT116 cells, and anti-KRAP polyclonal antibodies detected endogenous KRAP as a single band of the molecular size of $M_{r} 180,000$. Of great interest is that KRAP was colocalized with filamentous actin and was also localized at the cell surface.

\section{Materials and methods}

Isolation of differentially expressed genes

Isolation of differentially expressed genes between HCT116 and HKe3 cells was as described (Baba et al. 2000). KRAP cDNA was isolated by conventional plaque hybridization from the HCT116 cDNA library, and the full length of $K R A P$ cDNA was determined by 5 ' rapid amplification of cDNA ends. Mouse KRAP cDNA was isolated from a mouse heart cDNA library using a human $K R A P$ cDNA as a probe, and the full length of cDNA was determined as described above. DNA sequences were determined by ABI Prism Big Dye Terminator Cycle Sequencing (Applied Biosystems, Foster, CA. USA) with ABI 3100 sequencer. 
Fig. 1A-C Deregulated Ki-rasinduced actin-interacting protein $(K R A P)$ mRNA expression in human cancer cell lines and normal tissues. A Twenty micrograms of total RNA of HCT116, HKe3, and HKe3-derived transfectants expressing activated Ki-ras (e3MKRas\#9 and e3-MKRas\#14) were run in a $1 \%$ agaroseformaldehyde gel, then Northern blots were done using the coding region of $K R A P$ (upper panel) and $\beta$-actin (lower panel) as probes. B Twenty micrograms of total RNA of each cancer cell line were run in a $1 \%$ agarose-formaldehyde gel, and Northern blots were done using KRAP (upper panel) and $\beta$-actin (lower panel) as probes. C Human endocrine system multiple tissue Northern (MTN) blot filter (Clontech) (left panel) and human MTN blot II (Clontech) (right panel), on which $2 \mu \mathrm{g}$ of polyA RNA from each tissue was loaded, hybridized with $K R A P$ as probes
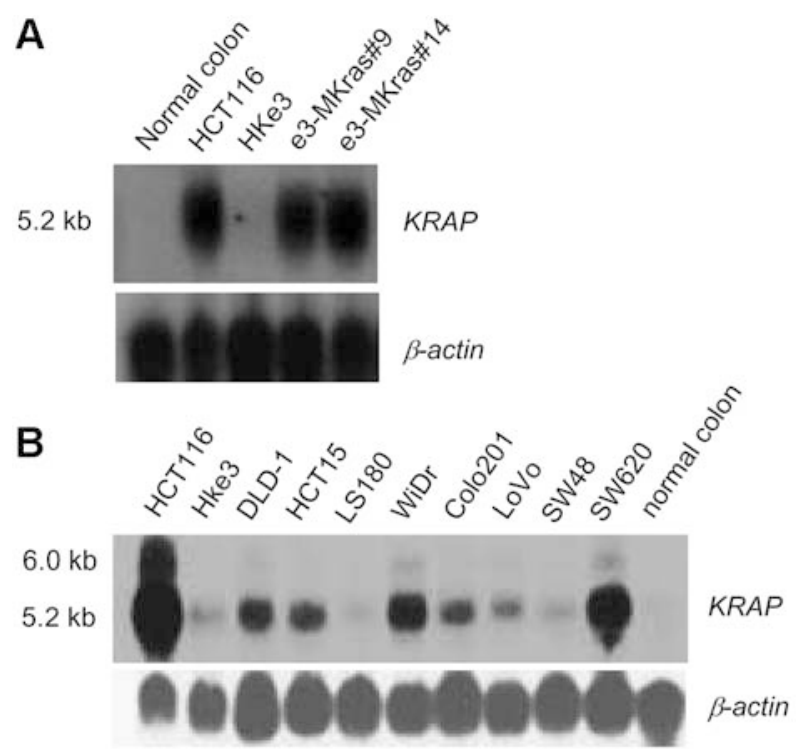

C

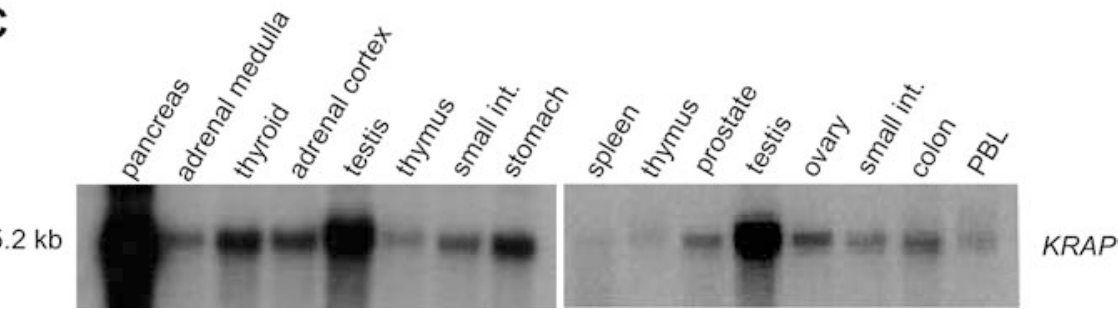

Northern blot

Total RNA of cell lines was isolated by ISOGEN (Nippon Gene, Tokyo, Japan) following the manufacturer's protocol. Total RNA $(20 \mu \mathrm{g})$ was separated by electrophoresis in a $1 \%$ agarose-formaldehyde gel, transferred to nylon membrane (Pall, East Hills, NY, USA), as described (Baba et al. 2000; Tsunoda et al. 2002). Human endocrine multiple tissue Northern (MTN) blot filter and human MTN blot II filter were purchased from Clontech (Palo Alto, CA, USA) on which $2 \mu \mathrm{g}$ of polyA RNA from each tissue was loaded. These filters were hybridized with probes for human $K R A P$ cDNA (full length of the coding region), and $\beta$-actin cDNAs, as described (Okumura et al. 1999).

\section{Anti-KRAP polyclonal antibodies}

Anti-KRAP polyclonal antibodies (FT017-2) were raised in rabbits using the polypeptide (amino acids 1,178-1,192 of human KRAP: VDAAEGAPEVVGPKS). Polyclonal antibodies were purified from serum by using protein-G Sepharose column.

\section{Transfections and stable transfectants}

$\mathrm{COOH}$ terminal hemagglutinin (HA)-tagged (Baba et al. 2000) KRAP cDNA was subcloned into pSI vector (Promega, Madison, WI, USA). Cells were transiently transfected using Polyfect (QIAGEN, Hilden, Germany) according to the manufacturer's protocol. Total cell lysates were extracted $24 \mathrm{~h}$ after transfection then subjected to immunoblot analysis using Western blots (Okumura et al. 1999). For stable transfectants, COOH terminal HA-tagged KRAP cDNA was subcloned into pMG vector (Invivogen, San Diego, CA, USA), and the linearized pMG-KRAPHA was transfected into NIH3T3 cells using Polyfect. Cells maintained in Dulbecco's modified eagle's medium (DMEM) with
$10 \%$ fetal calf serum (FCS) were split after 2 days, and cells were selected with $100 \mu \mathrm{g} / \mathrm{ml}$ of hygromycin B (Invitrogen, Carlbad, CA, USA). Colonies surviving in selection media in 14 days were picked up under the microscope and expanded and characterized for the expression of KRAP-HA by Western blot using anti-HA antibody (3F10) (Roche, Mannheim, Germany).

Immunofluorescence staining

Cells were grown on collagen-coated glass coverslips in growth medium. Twenty-four hours after transfection, cells were fixed with $3.7 \%$ paraformaldehyde in phosphate buffered saline (PBS) for 10 min at room temperature. After blocking with $1.4 \%$ milk in PBS containing $0.1 \%$ saponin, cells were incubated with anti-HA antibody (3F10) in PBS containing $0.1 \%$ bovine serum albumin (BSA) and $0.1 \%$ saponin for $1 \mathrm{~h}$ at room temperature, followed by incubation with Alexa Fluor 488 anti-rat IgG and/or Alexa Fluor 594 phalloidin (Molecular Probes, Eugene, OR, USA) at a dilution $1: 2,000$ for $1 \mathrm{~h}$ at room temperature. For counterstaining the nucleic acids, cells were incubated with $100 \mu \mathrm{g} / \mathrm{mL}$ of DNase-free RNase in $2 \times \mathrm{SSC}(0.3 \mathrm{M} \mathrm{NaCl}, 0.03 \mathrm{M}$ sodium citrate, $\mathrm{pH} 7.0)$ followed by incubation with $500 \mathrm{nM}$ solution of propidium iodide (PI) (Molecular Probes, Eugene, OR, USA) for 5 min at $37^{\circ} \mathrm{C}$. Cells were covered with a drop of GEL/MOUNT (Biomeda, Foster City, CA, USA), viewed by confocal laser scanning microscopy (FLUOVIEW FV500, OLYMPUS). Pretreatment of cytochalasin E (Sigma, Deisenhofen, Germany) $(100 \mathrm{ng} / \mathrm{ml}$ or $1.0 \mu \mathrm{g} / \mathrm{ml}$ in DMEM with $10 \%$ FCS) was done $3 \mathrm{~h}$ before fixing.

\section{Surface biotinylation and immunoprecipitation}

Biotinylation of cell-surface proteins was done as described (Baba et al. 2000). The surface-biotinylated lysates of the transfected HCT116 cells $\left(4 \times 10^{7}\right)$ were immunoprecipitated with $2 \mu \mathrm{g} / \mathrm{ml}$ of 
human 1 MDRPLSS SAEAEEELEWQVASRRR K AWA KCR S SW A S ETEDLSTEAT T Q DEEE DEEE DLP 60 mouse 1 M NRPLS. - AEAEEELEWQVASRRRKAWAKCRS SWQASETEDLSTETTTQDEDEDDEEDLP 58

human 61 G A Q L P A A G G R G N V P N E K I A I W L K D C R T P L G A S L D E Q S S S T L K G V L V R N G G S F E D L S L G A 120 mouse 59 G T KLPAPAGRGN VPNEK I A I WLKDCRTPLGASLDEQS SGTPLGVLVRNGGSFEDDLSLGA 118

human 121 E A N HL HES D A Q I EN C N N I L A KERRLQFHQKGRSMNSTGSG KS S T V S V SELLELYEE D P 180 mouse 119 EANHLHEPDAQVENCNN I L A K RRLQFHQKGRSMNSTGSGKSSGTVSSVSELLELYEEDP 178

human 181 E E I L Y N L GF GRDEP D I A S K I P SRFF N S S S F A K G I D I KVFL S A Q MQRMEVENPNY ALT SRF 240 mouse 179 EEILYNLGFGRDEPDIASKIPSRFFNSSSFARGIDIKVFLSAQMQRMEVENPNYALTSRF 238

human 241 R Q I E V L T T V A N A F S S L Y S Q V S G T P L Q R I G S M S S V T S N K ET D - P P P P L T R S N T A N R L M K T L 299 mouse 239 RQIEVLTTVANAFSSLYSQVSGTPLQRIGSMSSVTSTEEVADSPPPLTRSNTANRLMKTL 298

human 300 S K L N L C V D K T E K G ES S S P S PS A E K G K I L N V S V I E E S G N - KN D Q K S Q K I M K K K E S S S M L A T 358 mouse 299 S K L N L C V D K T E K G E G G S . S S P A A E K G R T L S I S L S E D G G G G K S D P K L

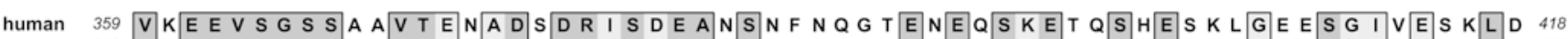
mouse 358 V T E EVS G S S S TV T D S V D A D R L S E E A D S T I S H Q E E S E E S REA H S Q E K D PLR K S A V T D P DLG 417

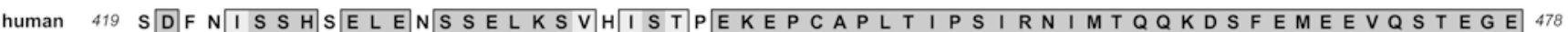
mouse 418 HDGRVS S HCELESSSELKS A A S S SEKEPCAPLTIPSIRNIMTQQKDSFEMEEVQSTEGE 477

human 479 APHVPATYQLG LT KSKRDHLLRTASQHSDSSGFAEDSTDCLSLN HLQVQESLQAMGSSAD 538

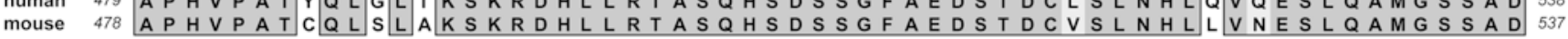

human 539 S C D SET T V T S L GEDL ATP T A Q D Q P Y F N E SEEESLVPLQKGLEKAAAVADKRKS G S D F P Q 598

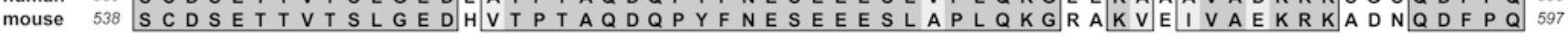

human 599 C N N T I E N T G T K Q S T C S P G D H I I E I T E V E E D L F P A E T V E L L R E A S A E S D V G K S S E S E F T Q Y T 658 mouse 598 C V T A E N A G N N E S T K G P C E P G H Q I T E T GE H P P L A A T G E L P R E E S V E S D V E K G S E C E F A Q Y T 657

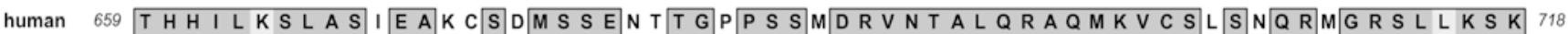

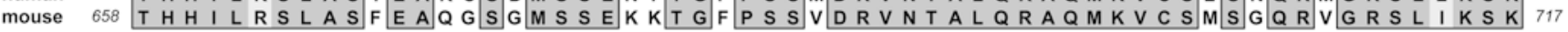

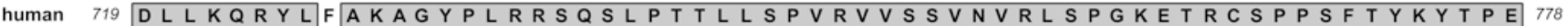
mouse 718 DLLKQRYLLLAKAGYPLRRSQSLPTTLLSPVRVVSSVNVRLSPGKETRCSPPSFTYKYTPE 777

human 779 EEQELEKR VMEHDGQ SLVK S T I F I S PS S V KKEEAPQSEAPRVEE CHHGRT P T C R L A P P 838

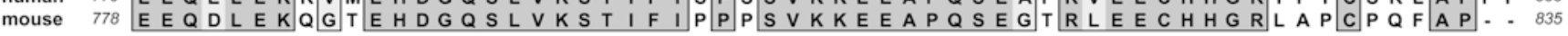

human 839 M S Q S T C S L H S I H S E W Q ER P L C E HTR T L S T H S V P N I S G AT C S A FA S P F G C P Y S H R H A T Y P Y 898 mouse 836 I S QSTCS L HS VHSEWQDRPL C E HMRTLS A H S P P I S G A A C A A S P P G C P Y S H R A A HP Y 894

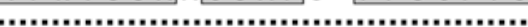

human 899 R V C S V N P P S A I E M Q L R R L H I RN S L Q N L S Q Y P M M R P D P A A P Y S T Q K S S V P L Y E N T F 958

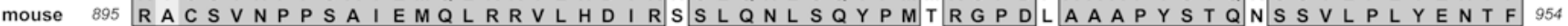

human 959 Q E L Q VM R R L N L F R T Q M D LEL A M L R Q T M V Y H H T EEERFE V D L Q G L N S V R M L Q D L 1018 mouse 955 QELQVVIRSLNLFRTQMMDLELAMLRQQTVVYPHMTEEDRYEVDQLQGLRNSVRMELQDL 1014

human 1019 EL Q L E ER L L G LEE Q L R A V R M P P F R S A L M G M C S R S A N L S P S P L N V MEP V T E L M Q E Q 1078

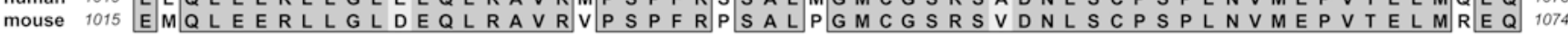

human 1079 S Y L K S E L G L G L GE M G F E I P P GE S SE S VF S Q A T S E S S S V C SGP S HANRR T - G V P T A S V G K 1137

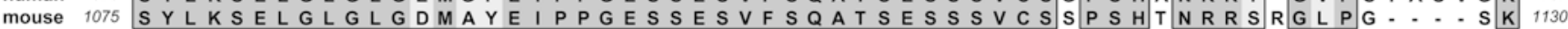

human 1138 S K T P L V A R K K V F R A S V A L T P T A P S R T G S V Q T P P D LE S SEE VDAAEGAPE V V G K SE VEEG 1197 mouse 1131 PRARLVARKK I FRAS VALTPTAPSRTGSVQTPPDLES SEEAGGAEEASPVVGLASHVEEE 1190

human 1198 H G K LP S M P A A E E M H K N VEQDELQQV I RE I KE S I V GE I R RE I V S G L L A V S S S K A S N S K Q D 1257

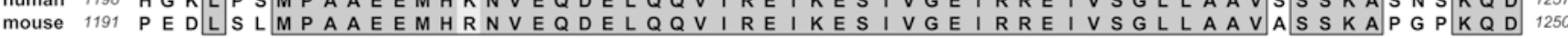

human 1258 Y $\mathrm{H} 1259$

mouse 1251 S $\quad$ H 1252

Fig. 2 Amino acids alignment of human and mouse Ki-ras-induced actin-interacting protein (KRAP). Transmembrane and coiled-coil regions are indicated by dotted and solid lines, respectively 


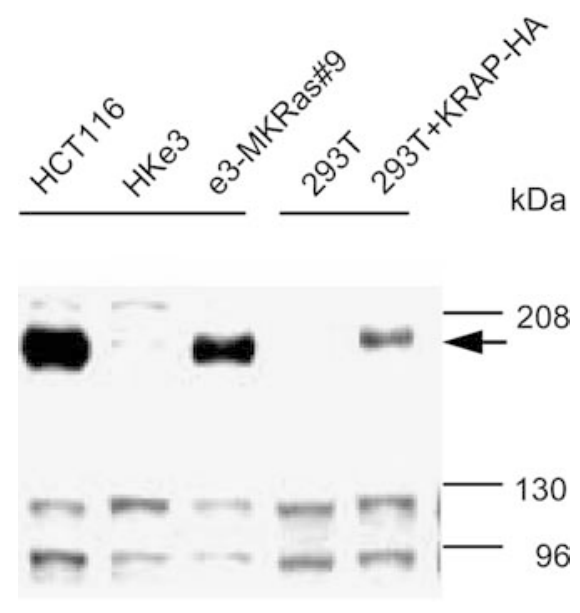

WB: anti-KRAP(FT017-2)

Fig. 3 Activated Ki-ras-induced actin-interacting protein (KRAP) expression. Anti-KRAP rabbit polyclonal antibodies detected the endogenous KRAP at the molecular size of $\mathrm{M}_{\mathrm{r}} 180,000$ (arrow). HCT116, HKe3, and HKe3-MKRas\#9 cells were grown at exponential growth conditions; 293T cells were transfected with pSI-KRAP-hemagglutinin (HA) or empty vector, and then whole cell lysates were run in a $6 \%$ SDS-PAGE

anti-HA antibody for overnight at $4{ }^{\circ} \mathrm{C}$, then protein G-Sepharose was added for $2 \mathrm{~h}$. Protein G-Sepharose complexes were boiled for $10 \mathrm{~min}$, and the supernatants were run in a $6 \%$ SDS-PAGE. Western blots were done using streptavidin-horseradish peroxidase (SA-HRP) (Amersham Biosciences, Piscataway, NJ, USA) and anti-HA antibody (3F10).

\section{Results}

To identify the genes located downstream of the activated Ki-ras-mediating signals, a PCR-based cDNA subtraction library was constructed between HCT116 cells and HCT116-derived activated Ki-rasdisrupted clone cells (HKe3) through homologous recombination (Shirasawa et al. 1993). The KRAP cDNA fragment was detected from this subtracted library, and the full length of KRAP cDNA was isolated from the HCT116 cDNA library (Baba et al. 2000). To confirm the differential expression of KRAP between HCT116 cells and HKe 3 cells, Northern blot analysis was done under exponential condition. Northern blot detected the $5.2 \mathrm{~kb}$-major KRAP transcript and the other minor $6.0 \mathrm{~kb}-K R A P$ transcript (Fig. 1). KRAP was strongly expressed in HCT116, whereas it was rarely observed in HKe3 (Fig. 1A). Furthermore, HKe3-stable transfectants expressing the activated Ki-ras (e3-MKRas\#9, e3-MKRas\#14) (Baba et al. 2000) evidently expressed KRAP (Fig. 1A). Northern blots revealed that KRAP expression was rarely evident in the normal colon epithelium, whereas it was strongly expressed in several kinds of human colon cancer cells (Fig. 1B). On the other hand, KRAP expression in human normal tissues was strongly observed in pancreas and testis (Fig. 1C).

Human KRAP cDNA was isolated from the HCT116 cDNA library and the full length of KRAP cDNA was determined by 5 rapid amplification of cDNA ends (AB116937). KRAP encodes a hypothetical protein of 1,259 amino acids (a.a.) with the transmembrane (a.a.870-890) and coiled-coil regions (a.a 992-1,038) (Fig. 2). To identify a mouse homologue of human $K R A P$, mouse cDNA library was screened using human $K R A P$ cDNA fragment as a probe, and mouse $K R A P$ cDNA encoding a protein of 1,252 a.a. was cloned (AB120565). Mouse KRAP cDNA had $81 \%$ identity with human KRAP at the nucleotides level and $86 \%$ similarity at the amino acid level (Fig. 2).

Anti-KRAP polyclonal antibodies (FT017-2) raised in rabbits using the peptides of the $\mathrm{COOH}$ terminal region of KRAP (a.a.1,178-1,192), recognized a single band of the molecular size of about $M_{r} 180,000$ in HCT116 and e3-MKRas\#9, but barely in HKe3 (Fig. 3). The 293 T cells were transiently transfected with KRAP$\mathrm{HA}$, HA-tagged in the $\mathrm{COOH}$ terminal region of KRAP, and KRAP-HA was evidently detected by FT017-2 at almost the same molecular size of KRAP detected in HCT116 cells, but was not detected in the nontransfected 293 T cells. Furthermore, any processed KRAP was not detected in other human cancer cell lines examined by FT017-2 (data not shown).

To elucidate the localization of KRAP in the cells, NIH3T3-derived stable transfectants expressing KRAP-HA (NIH3T3-KRAP-HA\#1) were stained with anti-HA antibody. KRAP-HA seemed to be colocalized with phalloidin-specific dye for F-actin in NIH3T3-KRAP-HA\#1 (Fig. 4A), indicating that KRAP is colocalized with actin filaments. Cytochala$\sin$ E, an epoxide-containing metabolite of Aspergillus clavatus, is a compound with diverse activities on cellular function, including inhibition of actin polymerization and glucose transport (Udagawa et al. 2000). To elucidate the interaction of KRAP with the actin filaments, treatment with cytochalasin $\mathrm{E}$ was done. Phalloidin staining indicated that disruption of actin filaments by cytochalasin $\mathrm{E}$ occurred in a dosedependent manner, and the interaction of KRAP with phalloidin gradually disappeared (Fig. 4B, C). These results together suggested that KRAP is associated with actin filaments in NIH3T3 cells.

To determine the localization of KRAP in cancer cells, COS7 cells and HCT116 cells were transfected with KRAP-HA and were stained with anti-HA and PI, indicating that KRAP is not localized in the nucleus (Fig. 4D). In COS7 cells, KRAP seemed to be localized near the cell membrane and the leading edge of the cells (Fig. 4E). In HCT116 cells, KRAP seemed to be also localized near the membrane regions (Fig. 4F). To elucidate whether KRAP exists as cell-surface protein, surface biotinylation was done, indicating that KRAP has the outer membrane region in HCT116 cells (Fig. 5). 
Fig. 4A-F Colocalization of $\mathrm{Ki}$-ras-induced actin-interacting protein (KRAP) with actin filaments. A A NIH3T3-derived stable transfectant expressing human KRAP hemagglutinin (HA) (NIH3T3-KRAP-HA\#1) was established. Cells were fixed and stained with anti-HA antibody (green) and phalloidin (red). Superimposed images are also shown (merge). NIH3T3KRAP-HA\#1 cells were pretreated with $100 \mathrm{ng} / \mathrm{ml}$ (B) and $1 \mu \mathrm{g} / \mathrm{ml}(\mathbf{C})$ of cytochalasin $\mathrm{E}$ in growth medium for $3 \mathrm{~h}$. Cells were washed three times with PBS and stained with antiHA antibody (green) and phalloidin (red). Superimposed images are also shown (merge). D COS-7 cells were transfected with pSI-KRAP-HA, and cells were grown on collagen-coated glass coverslips in growth medium. $24 \mathrm{~h}$ after transfection, cells were fixed and stained with anti-HA (green) and propidium iodide (PI) (red). Superimposed images are also shown (merge). COS7 cells (E) and HCT116 cells (F) were transfected with pSIKRAP-HA and were stained with anti-HA antibody (3F10). COS7 cells were also stained with PI
A

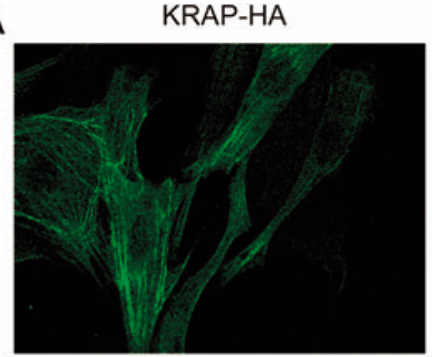

B
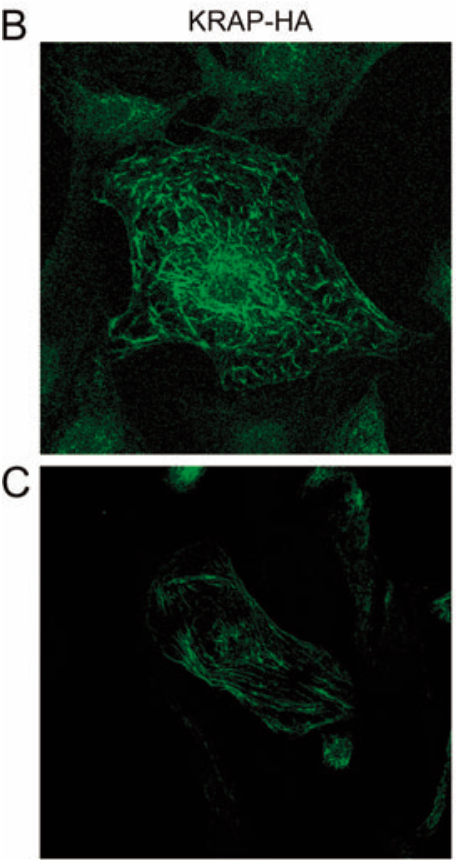

D

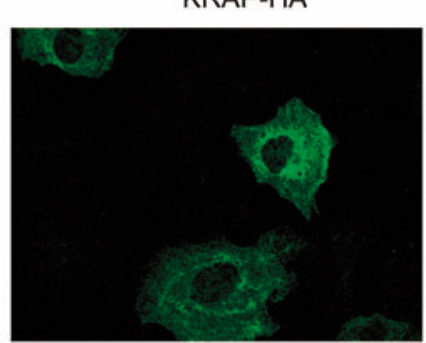

$$
\text { KRAP-HA }
$$
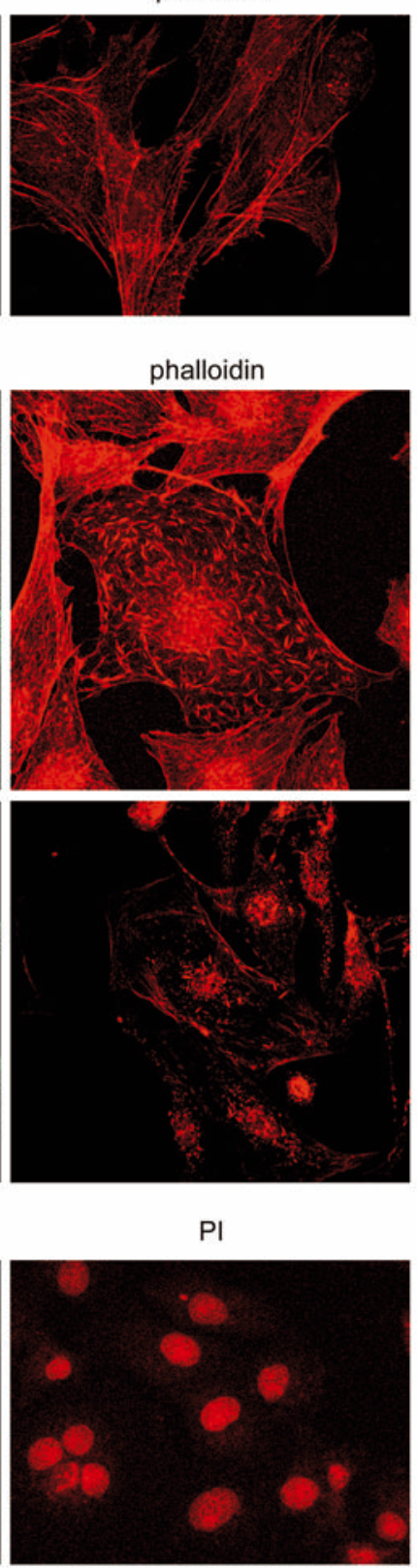

phalloidin
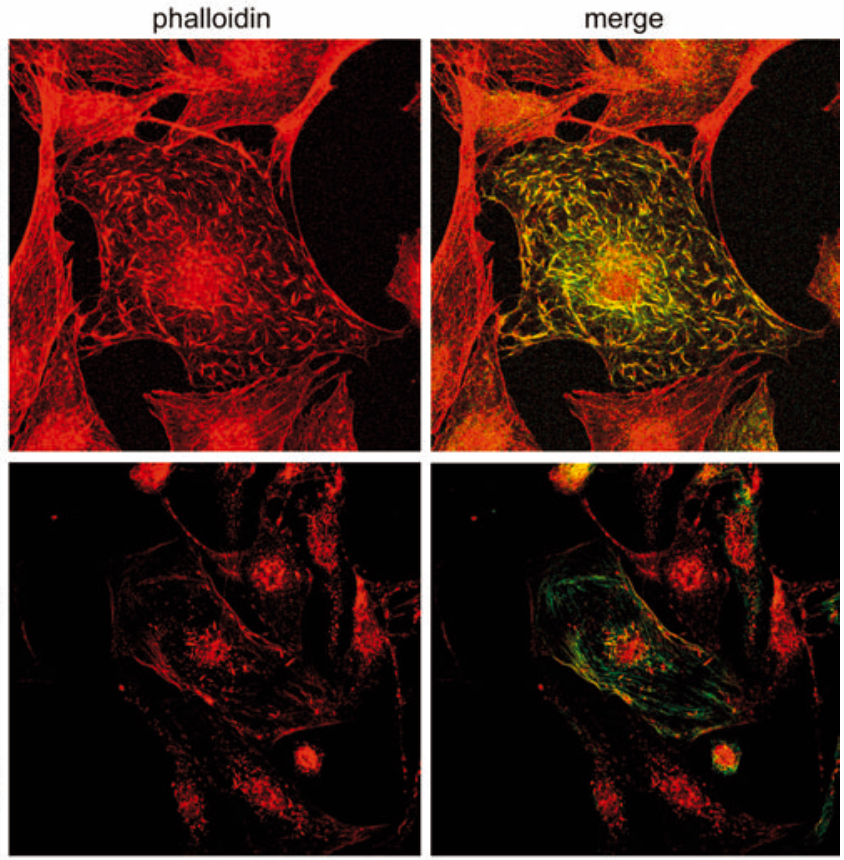

merge

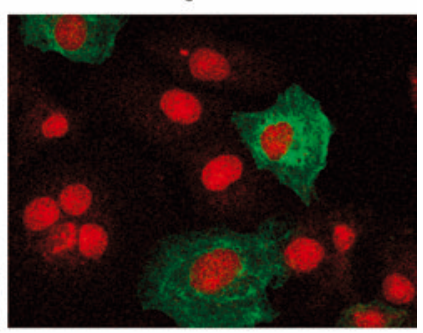

E

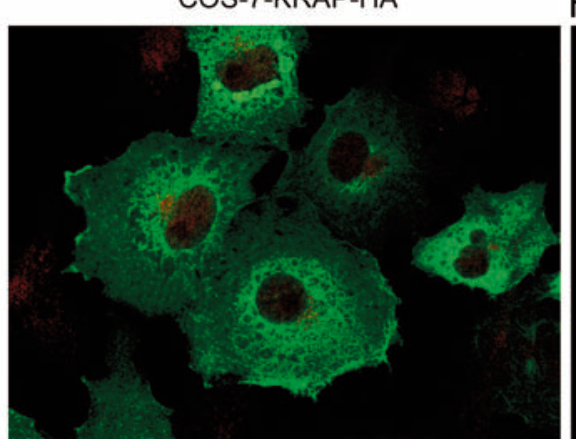

F

HCT116-KRAP-HA

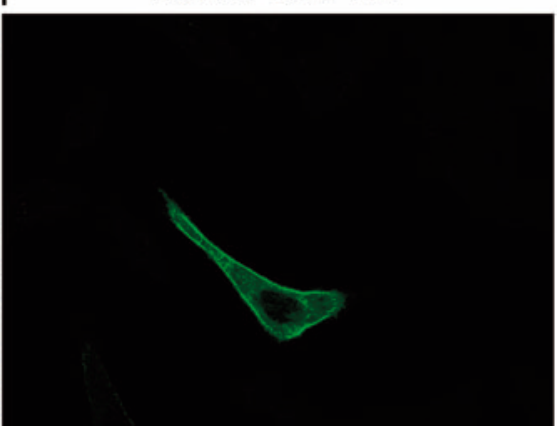




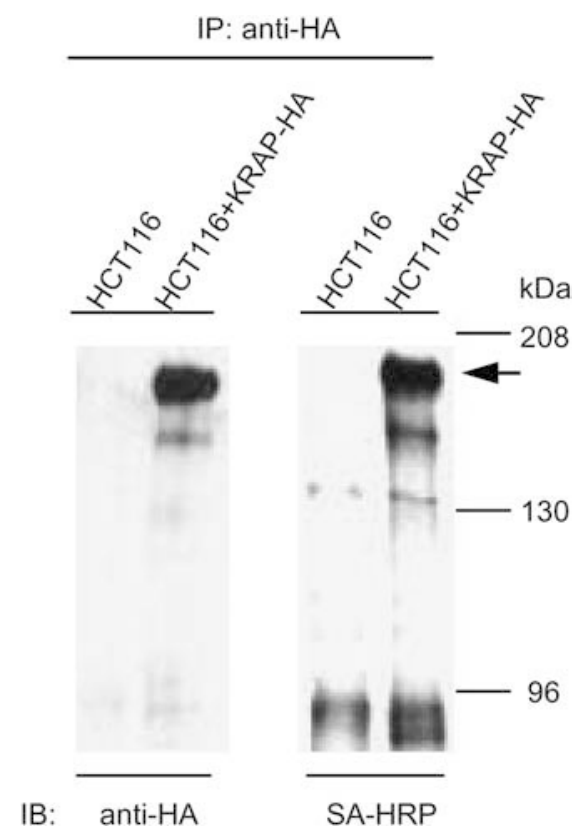

Fig. $5 \mathrm{Ki}$-ras-induced actin-interacting protein (KRAP) as cellsurface protein. HCT116 cells were surface-biotinylated and then immunoprecipitated with anti-hemagglutinin (HA) antibody. The immunoprecipitated products were detected by anti-HA antibody (left) and streptavidin-horseradish peroxidase (SA-HRP) (right). Arrow indicates biotinylated KRAP

\section{Discussion}

We have identified a novel gene, designated KRAP (Ki-ras-induced actin-interacting protein), encoding a protein of 1,259 amino acids with coiled-coil and transmembrane regions, from the cDNA library of human colon cancer HCT116 cells, as one of the genes upregulated by activated $\mathrm{Ki}$-ras.

Although Ki-ras mutation was detected in colon cancer cell lines, including HCT116, DLD-1, HCT-15, LS180, LoVo, and SW620 (Shirasawa 1993), KRAP was not overexpressed in LoVo cells, suggesting that other signals, in addition to the activated Ki-ras-mediated signals, might be necessary for the overexpression of $K R A P$. On the other hand, the colon cancer cells without Ki-ras mutation, including $\mathrm{WiDr}$ and Colo201 (Shirasawa 1993), expressed evident expression of $K R A P$, suggesting that other signals also could induce deregulated KRAP expression in human colon cancer cells. NIH3T3-derived stable transfectants expressing KRAP did not show tumorigenicity in nude mice nor did they show soft agar colony formation (data not shown), suggesting that overexpression of KRAP itself might not be sufficient for tumorigenicity and that other additional signals might be necessary for tumorigenicity. However, deregulated expression was observed not only in colon cancer cells but also in other kinds of cancer cell lines (data not shown), suggesting that KRAP might play critical roles in tumorigenesis through collaboration with other signals.
Mouse $K R A P$ cDNA had $81 \%$ identity with human $K R A P$ at the nucleotides level and $86 \%$ similarity at the amino acid level, indicating that $K R A P$ was highly conserved between human and mouse. $\mathrm{COOH}$ terminal regions (residues of a.a.1013-1259) of KRAP had been reported as the CS-1 (Javed and Naz 1992). CS-1 was originally identified as a sperm surface antigen of the molecular size of $\mathrm{M}_{\mathrm{r}} 33,000$, and anti-CS-1 polyclonal antibodies inhibited the early cleavage of fertilized eggs without affecting binding between sperm and egg or pronuclear formation (Javed and Naz 1992; Naz 1992).

We prepared the anti-KRAP polyclonal antibodies (FT017-2) raised in rabbits using the peptides of the $\mathrm{COOH}$ terminal region of KRAP, which recognized a single band of the molecular size of about $M_{r} 180,000$ in HCT116 cells, and processed KRAP was not detected in other human cancer cell lines examined. Although there is a possibility that CS-1 is located in the sperm surface as the molecular size of $M_{r} 33,000$, all these results together suggested that KRAP is an actual protein as the molecular size of about $M_{\mathrm{r}} 180,000$.

XCS-1, Xenopus homologue of CS-1, was reported to be detected on the membrane and in the nucleus of Xenopus blastomeres, on the mitotic spindle in mitotic cells, and on the centrosomes in interphase cells (Nakamura et al. 2000). Immunofluorescence microscopy revealed that neither KRAP nor CS-1-HA, HAtagged in the $\mathrm{COOH}$ terminal region of the original CS1 (Javed and Naz 1992), was localized in the nucleus in HCT116 cells, COS-7 cells, or NIH3T3 cells (data not shown). On the other hand, immunofluorescence microscopy and cytochalasin $\mathrm{E}$ treatment revealed that KRAP was clearly associated with the actin filaments in NIH3T3 cells. Furthermore, immunofluorescence microscopy and surface biotinylation revealed that KRAP exists as a membrane-bound form with the extracellular region in HCT116 cells. All these results together suggest that the localization of KRAP in the cells might vary depending on the cell types or other signals involved in the regulation of KRAP.

One of the critical processes in cancer developments is migration that requires the continuous, coordinated formation and disassembly of adhesions. These processes are complex and require a coordinated interaction of actin (Pollard 2003) or actin-interacting proteins, signaling molecules, structural proteins, integrins, adaptor molecules, and microtubules (Webb et al. 2002). Colocalization of KRAP with actin filaments and localization at the cell membranes with extracellular region suggest that KRAP might be involved in regulation of actin filaments and signals from the outside of the cells.

We have demonstrated previously that activated $\mathrm{Ki}-r a s$ is involved in the upregulation of c-myc, VEGF, the urokinase-type plasminogen activator receptor, epiregulin, and mig- 6 , all of which are critically involved in tumorigenesis. Here we have identified a novel actininteracting protein, KRAP, evidently induced by acti- 
vated $\mathrm{Ki}$-ras-mediated signals in human colon cancer HCT116 cells. Further elucidation of KRAP function in regulation of cytoskeleton and migration and KRAPmediated signaling pathways should shed light on the molecular mechanisms of tumorigenesis.

Acknowledgements This work was supported in part by a Grantin-Aid for Scientific Priority Areas from the Ministry of Education, Science, Technology, Sports and Culture, Japan.

\section{References}

Allgayer H, Wang H, Shirasawa S, Sasazuki T, Boyd D (1999) Targeted disruption in an invasive colon cancer cell line downregulates urokinase receptor expression and plasminogendependent proteolysis. Brit J Cancer 80:1884-1891

Almoguera C, Shibata D, Forrester K, Martin J, Arnheim N, Perucho M (1998) Most human carcinomas of the exocrine pancreas contain mutant c-Ki-ras genes. Cell 53:549-554

Baba I, Shirasawa S, Iwamoto R, Okumura K, Tsunoda T, Nishioka M, Fukuyama K, Yamamoto K, Mekada E, Sasazuki T (2000) Involvement of deregulated epiregulin expression in tumorigenesis in vivo through activated Ki-Ras signaling pathway in human colon cancer cells. Cancer Res 60:6886-6889

Barbacid M (1987) ras genes. Annu Rev Biochem 56:779-827

Bos JL (1989) ras oncogene in human cancer: a review. Cancer Res 49:4682-4689

Bos JL, Fearon ER, Hamilton SR, Verlaan-de Vries M, van Boom J, van der Eb AJ, Vogelstein B (1987) Prevalence of ras gene mutations in human colorectal cancers. Nature 327:293-297

Campbell SL, Khosravi-Far R, Rossman KL, Clark GJ, Der CJ (1998) Increasing complexity of Ras signaling. Oncogene $17: 1395-1413$

Forrester K, Almoguera C, Han K, Grizzle WE, Perucho M (1987) Detection of high incidence of Ki-ras oncogene during human colon tumorigenesis. Nature 327:298-303

Javed AA, Naz RK (1992) Human cleavage signal-1 protein; cDNA cloning transcription and immunological analysis. Gene 112:205-211

Johnson L, Greenbaum D, Cichowski K, Mercer K, Murphy E, Schmitt E, Bronson RT, Umanoff H, Edelmann W, Kucherlapati R, Jacks T (1997) K-ras is an essential gene in the mouse with partial functional overlap with N-ras. Genes Dev 11:2468-2481

Nakamura H, Wu C, Kuang J, Larabell C, Etkin LD (2000) XCS1 , a maternally expressed gene product involved in regulating mitosis in Xenopus. J Cell Sci 113:2497-2505

Naz RK (1992) Effects of antisperm antibodies on early cleavage of fertilized ova. Biol Reprod 46:130-139

Okada F, Rak JW, Croix BS, Lieubeau B, Kaya M, Roncari L, Shirasawa S, Sasazuki T, Kerbel RS (1998) Impact of oncogenes in tumor angiogenesis:mutant K-ras up-regulated of vascular endothelial growth factor/ vascular permeability factor is necessary, but not sufficient for tumorigenicity of human colorectal carcinoma cells. Proc Natl Acad Sci USA 95:36093614

Okumura K, Shirasawa S, Nishioka M, Sasazuki T (1999) Activated $\mathrm{Ki}$-Ras suppresses 12-O-tetradecanoylphorbol-13-acetate-induced activation of the c-Jun NH2-terminal kinase pathway in human colon cancer cells. Cancer Res 59:2445-2450

Pollard TD (2003) The cytoskeleton, cellular motility and the reductionist agenda. Nature 422:741-745

Rak J, Mitsuhashi Y, Bayko L, Filmus J, Shirasawa S, Sasazuki T, Kerbel RS (1995) Mutant ras oncogene upregulate VEGF/VPF expression: implications for induction and inhibition of tumor angiogenesis. Cancer Res 55:4575-4580

Shirasawa S (1993) Analysis of molecular mechanism in colorectal tumorigenesis. Fukuoka Igaku Zasshi 84:25-35

Shirasawa S, Furuse M, Yokoyama N, Sasazuki T (1993) Altered growth of human colon cancer cell lines disrupted at activated Ki-ras. Science 260:85-88

Tsunoda T, Inokuchi J, Baba I, Okumura K, Naito S, Sasazuki T, Shirasawa S (2002) A novel mechanism of nuclear factor $\kappa \mathrm{B}$ activation through the binding between inhibitor of nuclear factor- $\kappa \mathrm{B} \alpha$ and the processed $\mathrm{NH}_{2}$-terminal region of mig- 6 . Cancer Res 62:5668-5671

Udagawa T, Yuan J, Panigrahy D, Chang Y, Shah J, D'Amato RJ (2000) Cytochalasin E, an epoxide containing Aspergillus-derived fungal metabolite, inhibits angiogenesis and tumor growth. J Pharmacol Exp Ther 294:421-427

Webb DJ, Parsons JT, Horwitz AF (2002) Adhesion assembly, disassembly and turnover in migrating cells - over and over and over again. Nat Cell Biol 4:E97-E100

Zuber J, Tchernitsa OI, Hinzmann B, Schmitz A-C, Grips M, Hellriegel M, Sers C, Rosenthal A, Schafer R (2000) A genomewide survey of RAS transformation targets. Nat Genet 24:144152 